\title{
Mitgliederversammlungen auf dem 100. Deutschen Röntgenkongress, 29. Mai bis 1. Juni 2019
}

\section{(unter Vorbehalt zeitlicher Änderungen, Stand 01.03.2019)}

\section{Freitag, 31.05.2019}

07:30 - 09:15: Mitgliederversammlung der Deutschen Röntgengesellschaft (DRG)

\section{Mittwoch, 29.5.2019}

18:30 - 19:30: Mitgliederversammlung der Deutschen Gesellschaft für Interventionelle Radiologie und minimal-invasive Therapie (DeGIR)

\section{Donnerstag, 30.05.2019}

08:00 - 09:00: Mitgliederversammlung des Forums niedergelassener Radiologen in dei DRG (FuNRAD)

14:00 - 14:45: Mitgliederversammlung der Vereinigung Medizinisch-Technischer Berufe in der DRG (VMTB)

\section{Mitgliederversammlungen der AGs der DRG}

Zur ordentlichen Mitgliederversammlung der unten aufgeführten Arbeitsgemeinschaften der Deutschen Röntgengesellschaft, Gesellschaft für Medizinische Radiologie e. V. (DRG), lädt der jeweilige Vorstand die Mitglieder der jeweiligen Arbeitsgemeinschaften hiermit herzlich ein.

\section{Mittwoch, 29.05.2019}

17:15 - 18:15: Mitgliederversammlung der AG Informationstechnologie (AGIT)

18:15 - 19:15: Mitgliederversammlung der AG Ultraschall (AGUS)

18:15 - 19:15: Mitgliederversammlung der AG Onkologische Bildgebung

18:30 - 19:30: Mitgliederversammlung der AG Physik und Technik (APT)

\section{Donnerstag, 30.05.2019}

08:00 - 09:00: Mitgliederversammlung der AG Methodik und Forschung (AGMF)

08:00 - 09:00: Mitgliederversammlung der AG Herz- und Gefäßdiagnostik

13:45 - 14:45: Mitgliederversammlung der AG Bildgebende Verfahren des Bewegungsapparats (AG BVB)

14:15 - 15:15: Mitgliederversammlung der AG Kopf/Halsdiagnostik
Freitag, 31.05.2019

17:30 - 18:30: Mitgliederversammlung der AG Thoraxdiagnostik

\section{Samstag, 01.06.2019}

08:30 - 09:30: Mitgliederversammlung der AG Gastrointestinal-/Abdominaldiagnostik 08:30 - 09:30: Mitgliederversammlung der
AG Diagnostische Radiologie arbeits- und umweltbedingter Erkrankungen (AG DRauE) 08:30 - 09:30: Mitgliederversammlung der AG Uroradiologie/Urogenitaldiagnostik 08:30 - 09:30: Mitgliederversammlung der AG Mammadiagnostik 10:15 - 11:15: Mitgliederversammlung der AG Pädiatrische Radiologie 